\title{
PRINCÍPIO DA JURIDICIDADE: O SUPRAPRINCÍPIO NORMATIVO NO DIREITO PÚBLICO
}

\author{
Principle of legality: the supraprincipio standard in public law
}

Francisco Luiz Fernandes

Mestre em Direito - área de concentração: Direitos Sociais e Cidadania - pela UNISAL - Centro Universitário Salesiano/Lorena/SP; Especialista em Direito Processual pela PUC-Minas; Coordenador do curso de Direito da UNINCOR, Professor na seara do Direito na UNINCOR na disciplina de Direito Constitucional; Professor no curso de Direito na FEPI - Centro Universitário de Itajubá/MG, nas disciplinas: Direito Constitucional, Direito Administrativo e Direito Tributário. E-mail: prof.flfernandes@gmail.com.

RECEBIDO EM: 08.07.2013

APROVADO EM: 20.08.2013

\section{RESUMo}

A proposta elencada neste trabalho reflete a possibilidade jurídica de utilização de um supraprincípio na seara do direito público que englobe em seu conceito os princípios basilares do direito público que são: princípio da legalidade, da moralidade, publicidade e eficiência. Princípio já estudado em doutrinas portuguesas que busca concatenar os grandes princípios públicos visando à integração destes para formação do ato administrativo perfeito. Visa, sobretudo promover e demonstrar a possibilidade do agente público ao atuar com o seu múnus público estar revestido dos princípios basilares contidos no Art. 37 da $\mathrm{CF} / 88$. A proposta é tornar o princípio da juridicidade mais um supraprincípio no direito público, sendo aquele pelo qual o gestor público deve nortear-se em seus atos. A proposta deste trabalho fundamentase no estado social democrático do qual proporciona a qualquer pessoa o exercício do direito, não se apartando dos princípios fundamentais do direito público, mormente com fincas no neoconstitucionalismo quando na tomada de decisões deve-se levar em conta todo o arcabouço jurídico existente no afã de proporcionar uma decisão mais justa e equânime. Proposta descrita nesta obra funda-se na concatenação dos princípios basilares formando um princípio gerador de comandos para os demais princípios no direito público. 
Palavras-chave: PrincíPIO da Juridicidade. Supraprincípio da AdMinistraÇão PÚbliCA. PRINCÍPIOS DO DIREITO PÚBLICO.

\begin{abstract}
The proposal disagree this work reflects the possibility of using a legal principle above the mobilization of public law in its concept that encompasses the basic principles of public law which are: the principle of legality, morality, transparency and efficiency. Principle already studied in Portuguese doctrines seeking concatenate the great principles aimed at integrating these public training for the administrative act perfect. Visa, mainly promote and demonstrate the ability of the public official to act with the public his office be covered on the basic principles contained in Article 37 of $\mathrm{CF} / 88$. The proposal is to make the principle of legality principle above another in public, and one for which the public administrator should be guided in their actions. The purpose of this research is based on social democratic state which gives any person the right, not departing from the fundamental principles of public law, especially with fincas in neoconstitutionalism when making decisions should take into account all existing legal framework in the rush to provide a more fair and equitable decision. Proposal described in this work is based on the basic principles of concatenização forming a generating principle of commands to the other principles in public law.
\end{abstract}

Keyword: Principle of legality. Supra principle of Public administration. Public LAW PRINCIPLES.

Sumário: Introdução. 1. Definição de princípios e supraprincípios 1.1. Definição de princípios. 1.2. Definição de supraprincípios no direito público. 2. Supraprincípio da juridicidade. Referências.

\title{
INTRODUÇÃo
}

O princípio da juridicidade é uma inovação evolutiva no direito administrativo, marca o seu nascedouro na proposta de ultrapassar a abrangência do princípio da legalidade, formando um compêndio de obrigações legais e naturais, tais como, um "bloco de legalidade" ${ }^{438}$, promovendo assim um tratamento latu sensu a legalidade necessária ao ato administrativo praticado de formal geral.

Neste esteio, tomando-se por base tal proposta, o princípio da legalidade

$\overline{438}$ BINENBOJN, Gustavo. Uma teoria de direito administrativo: direitos fundamentais, democracia e Constituição. Rio de Janeiro: Renovar, 2006. pp.. 137-139. 
tornar-se-ia fundamento strictu sensu para basilar os atos administrativos, baseandose tão-somente na regra pura da lei, do qual se defluiu, quando de sua criação, qual seja, a atividade administrativa fulcrada na lei como formadora exclusiva da legalidade administrativa, não se levando em conta, neste princípio, os fundamentos e princípios do direito, como elementos agregadores do "bem agir" do gestor público, portanto só será válido o que estivesse revestido de lei, não se considera os costumes, as decisões dos tribunais, as súmulas, e demais atos norteadores de cumprimento formal nem tampouco os fundamentos do direito como elemento formador desta legalidade.

Na afirmativa de Maria Sylvia Zanella Di Pietro ${ }^{439}$ :

Através do princípio da legalidade a Administração Pública só pode fazer o que a lei permite, ou seja, todos os atos do administrador dependem da lei e a Administração Pública não pode, através de ato administrativo, conceder direitos de qualquer espécie, criar obrigações ou impor vedações aos administrados". Assim, "a vontade da Administração Pública é aquela que decorre da lei.

Destarte que para chegar nesta concepção de legalidade à proposta administrativa teve seu nascedouro a partir da analogia dogmática entre o ato administrativo e a sentença judicial, ou seja, o ato administrativo seria a apuração dos mandamentos genéricos e abstratos da lei. Tal concepção malfada não teve evolução mormente em virtude do princípio da inafastabilidade de apreciação do poder judiciário o ato administrativo eivado de lei ou deferido de forma diversa da lei não tem efetividade no meio jurídico nacional por não praticarmos administração contenciosa e sim a administração jurídica no Brasil ancorada no Art. $5^{\circ}, \mathrm{XXXV}$ da CF/88, determinando constitucionalmente a aplicabilidade do sistema de jurisdição uma ou sistema de controle judicial originário do sistema inglês .

Fulcrado neste esteio, a Administração Pública pratica a forma hierarquizada na formação de seus atos, respeitando o princípio da hierarquia, que são, por via de fundamento atos vinculados. De toda essa aplicabilidade fez-se desaguar no entendimento doutrinário e jurisprudencial de que a Administração Pública deveria agir alicerçado, mormente no princípio da legalidade tendo, tão-somente a lei como fundamento basilar deste princípio da Administração Pública.

Entretanto como o direito é mutante e atuante assim como, atual, e, partindo do pressuposto da necessidade de abarcar uma amplitude jurídico-social para tempos atuais, é que vislumbro esta obra com a proposta de materializar dentro do ordenamento jurídico basilar o princípio da juridicidade como um supraprincípio da

${ }^{439}$ DI PIETRO, Maria Sílvia Zanella. Direito Administrativo. 14. ed. São Paulo: Atlas. 2002. pp. $67-68$ 
administração pública somado aos outros dois supraprincípios ${ }^{440}$ que abarcam o direito como interesse público e o poder público como supremacia, ensejando na seara do terceiro supraprincípio como bloco de legalidade.

No entender de Germana de Oliveira Moraes ${ }^{441}$ : "A noção de juridicidade, além de abranger a conformidade dos atos com as regras jurídicas, exige que sua produção (a desses atos) observe - não contrarie - os princípios gerais de Direito previstos explícita ou implicitamente na Constituição".

$\mathrm{Na}$ mesma linha, Emerson Garcia ${ }^{442}$ explica que a cunhagem da palavra juridicidade deve-se a Adolf Merkl ${ }^{443}$, "o qual incluía sob o signo do princípio da juridicidade todo o ordenamento jurídico, abrangendo os regulamentos, os princípios gerais, os costumes etc.; tendo reservado a nomenclatura de princípio da legalidade unicamente à lei em sentido formal".

A proposta de juridicidade administrativa é formada partindo-se da interpretação dos princípios e regras constitucionais, englobando, sobretudo, o princípio da legalidade. A Constituição preocupou-se, em seu artigo 37, em colocar de forma expressa os princípios que necessariamente deveriam ser seguidos pela administração pública, mas não limitou-se a eles: "A administração pública direta e indireta de qualquer dos Poderes da União, dos Estados, do Distrito Federal e dos Municípios obedecerá aos princípios de legalidade, impessoalidade, moralidade, publicidade, eficiência (...)"

Neste diapasão, a legalidade não pode ter tratamento de princípio soberano, restando ser mais um princípio a ser seguido, dentre muitos outros presentes no ordenamento jurídico.

Posto isto, o princípio da juridicidade nasce corroborado na atuação da atividade da Administração Pública no pressuposto emanado da Constituição, com ênfase nos direitos fundamentais e no regime democrático de direito, por serem estes ditames a base de todo o nosso ordenamento. O princípio da juridicidade, por ter uma proposta de bloco de legalidade, vai além da legalidade, vincula a atividade estatal ao conjunto de princípios e regras, valorizando a realização dos direitos do homem sobre a mera aplicação da lei administrativa, da qual este consagrado nos princípios gerais do direito.

\footnotetext{
${ }^{440}$ Supremacia do interesse público e indisponibilidade do interesse público

${ }^{441}$ MORAES, Germana de Oliveira. Controle Jurisdicional da Administração Pública, 1. ed., São Paulo: Dialética, 1999, p. 24. In: GARCIA, Emerson. Op. cit. p. 1.

442 GARCIA, Emerson. A moralidade administrativa e sua densificação. Disponível em: http://jus2.uol.com.br/doutrina/texto.asp?id=4283. Acessado em: 25.10.2012. p. 1.

${ }^{443}$ Cf. Eduardo García de Enterría y Tomás-Ramon Fernández, Curso de Derecho Administrativo, vol. I, 2a ${ }^{\text {a }}$ ed., Madrid, Editora Civitas, 1978, p. 251.
} 


\section{DEFINIÇão DE PRINCÍPIOS E SUPRAPRINCÍPIOS}

Os supraprincípios da Administração Pública, embora norteadores do exercício da atividade administrativa pública, não se exaurem em si mesmos, atualmente estes princípios norteadores são dois, mormente, nos ditames de Celso Antônio Bandeira de $\mathrm{Melo}^{444}$ : a) princípio da supremacia do interesse público sobre o privado; e b) indisponibilidade do interesse público.

Cabe destacar que embora doutrinados e aplicados como supraprincípios, a supremacia, assim como no direito de forma geral, não é absoluta, cabe análise casuística da aplicabilidade, ou melhor, explicitado, cabe, aplicação elástica dos supraprincípios face aos acontecimentos sociais e jurídicos.

\subsection{DEFINIÇÃo DE PRINCÍPIO}

Toda forma de conhecimento epistemológico necessita basear-se em princípios. Os princípios servem como fundamento lógico para formar a validade para afirmar as demais asserções que compõe a proposta do saber. de conhecimento.

Segundo Miguel Reale ${ }^{445}$, princípios são verdades fundantes de um sistema

Destarte salientar que a LINDB - Lei de Introdução as Normas de Direito Brasileiro ${ }^{446}$, elenca em seu Art. $4^{\circ}$ somado ao Art. $8^{\circ}$ parágrafo único da CLT - consolidação das Leis do trabalho ${ }^{447}$, também o CPC - Código de Processo Civil ${ }^{448}$ traz em seu Art. 126 que, em caso de omissão de regra o juiz deve decidir a lide baseado em analogia, costumes e princípios gerais do direito.

Princípio tem seu fundamento amparado na deontologia axiológica de conduta. Portanto existem para o mundo, antes das normas ou das regras jurídicas, todas as regras de conduta têm seu nascedouro em uma moral (prescrições valorativas - axiológica), evoluem para conduta (prescrições descritivas - interpretação) até che-

444 MELO, Celso Antônio Bandeira. Curso de Direito Administrativo. 26. ed. São Paulo: Malheiros. 2009. p. 69.

${ }^{445}$ REALE, Miguel. Lições Preliminares de direito. 27. ed. 11 tiragem. São Paulo: Saraiva. 2012. p 303.

${ }^{446}$ Decreto-Lei no 4.657, de 4 de setembro de 1942. Alterado pela lei Lei ${ }^{\circ} 12.376$, de 30 de dezembro de 2010.

${ }^{447}$ Art. $8^{\circ}$ As autoridades administrativas e Justiça do Trabalho, na falta de disposições legais ou contratuais, decidirão, conforme o caso, pela jurisprudência, por analogia, por equidade e outros princípios e normas gerais de direito, principalmente do direito do trabalho e, ainda, de acordo com os usos e costumes, o direito comparado, mas sempre de maneira que nenhum interesse de classe ou particular prevaleça sobre o interesse público. § único - O direito comum será fonte subsidiária do direito do trabalho, naquilo em que não for incompatível com os princípios fundamentais deste.

${ }^{448}$ Lei 5.869 de 11 de janeiro de 1973. 
garem a regra ou norma (prescrições prescritivas - positivação) visando a certificação erga ommis de uma conduta aprovada ao ser transformada em regra de conduta geral obrigatória a todos os abrangidos pela temática proposta.

Nos ensinamentos do professor Pablo Jiménez Serrano 449 "É natural que os princípios não sejam iguais, mesmo nas constituições do mesmo tipo, já que sofrem influência das características específicas de cada povo, sejam de ordem econômica, cultural ou história". Neste afã, os princípios são diversos mas todos têm o mesmo fundamento - o de originar as regras de conduta - de um povo, visando, sobretudo, regrar a conduta de forma a propiciar a todos os abrangidos pela conduta uma forma linear de atuação.

Da mesma maneira, os princípios jurídicos são o ponto de partida mais importante do sistema normativo, são verdadeiros alicerces pelo qual se constrói o sistema jurídico.

Princípios são valores fundamentais de um sistema através de abstração indutiva. Princípios são valores fundamentais de um sistema jurídico. Ocorrem em forma de uma dupla finalidade: hermenêutica (entendimento e aplicação) e integrativa (teleologia ao suprir lacunas de lei).

Neste esteio, Celso Antônio Bandeira de $\mathrm{Melo}^{450}$ define princípio como:

Mandamento nuclear de um sistema, verdadeiro alicerce dele, disposição fundamental que se irradia sobre diferentes normas compondo-lhes o espírito e sentido servido de critério para sua exata compreensão e inteligência, exatamente por definir a lógica e a racionalidade do sistema normativo, no que lhe confere a tônica e lhe dá sentido harmônico.

Posto isto, a proposta de utilizar o princípio da juridicidade como um novo supraprincípio da administração pública se reveste de fundamento lógico e racional, mormente pela necessidade de, em todos os atos da vida administrativa, o agente público ou o privado, ter que se submeter aos ditames contidos no Art. 37 da Constituição Federal de 1988.

\subsection{DEFINIÇÃo DE SUPRAPRINCÍPIOS NO DIREITO PÚBLICO}

Temos elencado na Constituição Republicana de 1988 alguns princípios republicanos basilares norteadores que estão dispostos no Art. $4^{\circ}$ da $\mathrm{CF} / 88^{451}$.

\footnotetext{
449 SERRANO. Pablo Jiménez. Teoria dos Direitos Humanos. São Paulo: Rumo Gráfica Editora. UNIBAN. 2010. p. 54.

${ }^{450}$ Curso de direito Administrativo. pp. 882-883.

${ }^{451}$ Art. $4^{\circ}$ A República Federativa do Brasil rege-se nas suas relações internacionais pelos seguintes princípios: I - independência nacional; II - prevalência dos direitos humanos; III - autodeterminação dos povos; IV - não-intervenção; V - igualdade entre os Estados; VI - de-
} 
Os supraprincípios também conhecidos como princípios norteadores da administração pública fundam-se hoje em dia em dois pressupostos: a) supremacia do interesse público sobre o privado e b) indisponibilidade do interesse público.

Em se tratando do princípio da supremacia do interesse público sobre o privado, o interesse coletivo sobrepõe os individuais. Preconiza ó interesse público primário, ou seja, a coletividade.

Já em relação ao Princípio da indisponibilidade do interesse público, os agentes públicos estão obrigados a atuarem conforme determinado em norma, portanto não é possível transacionar em juízo bens públicos.

O bloco de legalidade suprema, que consiste os supraprincípios da administração pública, não são absolutos, e é neste sentido que podemos parear a proposta de um novo supraprincípio para administração pública do qual irá englobar não só as leis materiais mais todo arcabouço normativo como decretos atos normativos regulamentos instruções normativas, ética, moral, moralidade pública, conduta e costumes.

O doutrinador Alexandre Mazza ${ }^{452}$, descreve as inúmeras regras ou normas que podem ser abrangidas pelo princípio da juridicidade. Neste sentido o princípio da juridicidade extrapola a seara positivista e alcança condutas sociais e comportamentais do qual o gestor público se obriga a cumprir quando de sua atuação.

\section{O SUPRAPRINCÍPIO DA JURIDICIADE}

Porque entender o princípio da juridicidade como um supraprincípio da Administração Pública. Porque não se restringe a apenas uma modalidade principiológica e se sobrepõe quando de sua matriz, ao fundar-se em um grande princípio que englobaria todas as leis (princípio da legalidade), as regras internas e os costumes. $\mathrm{O}$ que se busca neste novo supraprincípio vai além dos princípios já apontados por diversos doutrinadores, corrobora em uma convergência de ações que devam ser praticadas pelo agente público sem o qual tornar-se-ia maculado o ato administrativo.

Ainda neste esteio, o princípio da juridicidade não pode estar aparelhado a princípios gerais constitucionais ou quiçá princípios específicos da administração pública pois nasceu para fortalecer o atual momento jurídico do Brasil e de boa parte do mundo aonde se busca a integração entre norma e fato social.

Por todo este diapasão é que entendo ser o princípio da juridicidade um novo supraprincípio da administração pública pois os dois primeiros tem abrangência em seara diversas não contemplando a proposta deste princípio.

Ao abordarmos o princípio da supremacia do interesse público sobre o privado, o que se pretende a priorizar o interesse coletivo ao sobreporem-se aos indi-

fesa da paz; VII - solução pacífica dos conflitos; VIII - repúdio ao terrorismo e ao racismo; IX - cooperação entre os povos para o progresso da humanidade; X - concessão de asilo político. ${ }^{452}$ MAZZA, Alexandre. Manual de direito Administrativo. 2. ed. São Paulo: Saraiva. 2012. p. 85 . 
viduais. Preconizando ó interesse público primário, ou seja, a coletividade. Quando ressaltamos o princípio da indisponibilidade do interesse público, os agentes não podem transacionar o que é indisponível, ou seja, os bens públicos.

Corroborando esta seara, o princípio da juridicidade reveste-se de toda regra inclusive os costumes, a ética e a eficiência, todo esse desiderato de ordenamentos visa promover a conduta do agente público fulcrado na norma fundamental do agir conforme a lei, e neste novo princípio, a leis revestem-se de toda forma de conduta no mundo jurídico, as positivadas e não positivadas ou sociais.

Parafraseando o doutrinador Alexandre $\mathrm{Mazza}^{453}$, podemos entender que o princípio da juridicidade compõe-se de um bloco de legalidade e, superando esta proposta, vamos adiante no anotar que o princípio da juridicidade não é só um somatório de legalidade mas e sobretudo reveste-se de legalidade e legitimidade quando denotado como costume ou procedimentos não normatizados.

É, portanto um novo supraprincípio alicerçado na proposta do neoconstitucionalismo ou do pós-positivismo, busca garantir direitos fundamentais do cidadão assim como deveres explícitos e implícitos da administração pública para com os seus administrados ou com ele mesma em suas ações costumeiras.

Em primeiro lugar, há que se notar que a juridicidade possui um reflexo importantíssimo, sobretudo no que concerne aos direitos fundamentais, já que, apesar de não existir uma hierarquia entre as normas constitucionais, é indubitável que aqueles possuem uma primazia axiológica com relação às demais normas da Lei Maior.

Os novos encargos assumidos pelo Estado determinam o crescimento de seu aparelho administrativo, fazendo aumentar, consideravelmente, a responsabilidade dos agentes públicos.

Nesta proposta, o supraprincípio da juridicidade representaria um macro sistema de alguns princípios da Administração Pública e especificamente estariam sob sua abrangência os princípios constitucionais dispostos no Art. $37 \S 4^{\circ}$ da CF/88 que são, o princípio da legalidade, da impessoalidade, da moralidade, da publicidade e da eficiência, tornando estes princípios, espécies do supraprincípio da juridicidade.

Em virtude do princípio do Estado de Direito e de sua eficácia de ordenação dos elementos que o compõem, é possível permitir a atuação do administrador independentemente de lei que regulamente o direito à saúde $-e$. g., para normatizar uma política de concessão de medicamentos ainda que não haja lei definidora de tal política, até que sobrevenha diploma legal dispondo sobre a dita concessão ${ }^{454}$

O supraprincípio da juridicidade atem-se a nova ordem de subordinação

\footnotetext{
453 Ibidem. p. 85

${ }^{454}$ RODRIGUES, Marco Antônio dos Santos. Artigo: Neoconstitucionalismo e legalidade administrativa: a juridicidade administrativa e sua relação com os direitos fundamentais. Disponível em: download.rj.gov.br/rev630309NeoconstitucionalismoPrincipiolleg. Acessado em: 26.12.2012.
} 
da administração pública ao direito no atual Estado Democrático de direito ou tãosomente o Estado social. As mudanças operadas na segunda metade do século XX, já antes referidas - alteração do sentido e do conceito material de lei; alargamento do domínio juridicamente relevante; desenvolvimento exponencial das esferas de actuação administrativa - têm como consequência a ampliação e a diversificação das relações entre a Administração e o Direito, gerando um novo paradigma ${ }^{455}$.

A compreensão ora proposta de juridicidade permite que se tracem alguns desdobramentos possíveis que exsurgem a partir da concepção trabalhada. Assim, serão explicitadas possíveis consequências do fenômeno da juridicidade, pois, evidentemente, não seria possível sequer almejar-se exaurir a matéria, a qual é inesgotável.

A partir da noção de juridicidade apontada, verifica-se a possibilidade de juridificação de fatos não formalizados, isto é, a atribuição de axiologia jurídica a fatos que, a priori, não poderiam ser reconhecidos juridicamente. Em outras palavras, é dizer que a juridicidade pode conferir relevância jurídica à mera existência fática de determinadas situações, algo inimaginável sob o prisma legalista/positivista.

Nesse sentido o supraprincípio da juridicidade comtempla não só as normas posititvas mas, sobretudo, o costume administrativo, as praxes, práticas e usos administrativos e o precedente administrativo ${ }^{456}$.

Tais fatos, praticados pela própria Administração, têm o poder de "subverter" a legalidade e a dicotomia entre validade e invalidade, pois mesmo não sendo tais atos formais sob a perspectiva estrita da legalidade (razão pela qual seriam ilícitos e inválidos pelo paradigma da legalidade), são merecedores de consideração pela simples existência, a qual é capaz de lhes conferir validade jurídica, a despeito da ilegalidade formal.

Ressalte-se, ainda, que o reconhecimento de tais atos ou precedentes da Administração tem força jurídica para normatizar ou até mesmo vincular a própria Administração, que não poderá alegar a ilegalidade da sua própria conduta, salvo, evidentemente, as hipóteses em que houver argumentos - de interesse público - suficientes para desconsideração de tal situação, à luz de uma análise sistemática.

Tal compreensão tem por fundamento, no direito brasileiro as ações discricionárias do administrador público que devem pautar-se nos princípios da juridicidade pública.

\section{REFERÊNCIAS}

BINENBOJN, Gustavo. Uma teoria de direito administrativo: direitos fundamentais, democracia e Constituição. Rio de Janeiro: Renovar, 2006

\footnotetext{
455 www.estig.ipbeja.pt/ ac_direito/DA_I.pdf. Acessado em: 26.12.2012.

456 OTERO, Paulo. Legalidade e Administração Pública: o sentido da vinculação administrativa à juridicidade. Coimbra: Almedina, 2011. p. 1084.
} 
CARVALHO FILHO, José dos Santos. Manual de Direito Administrativo. 15. ed. Rio de Janeiro: Lummen Juris. 2006

MELO, Celso Antônio Bandeira. Curso de Direito Administrativo. 28. ed. São Paulo: Malheiros. 2012.

DI PIETRO, Maria Sílvia Zanella. Direito Administrativo. 20. ed. São Paulo: Atlas 2010.

Eduardo García de Enterría y Tomás-Ramon Fernández, Curso de Derecho Administrativo, vol. I, 2. ed., Madrid, Editora Civitas, 1978

MARINELA, Fernanda. Direito Administrativo. 5. ed. Niterói/RJ: Impetus. 2011.

MAZZA, Alexandre. Manual de Direito Administrativo. 2. ed. São Paulo: Saraiva. 2012.

MELO, Celso Antônio Bandeira. Curso de Direito Administrativo. 26. ed. São Paulo: Malheiros. 2009

MORAES, Germana de Oliveira. Controle Jurisdicional da Administração Pública, 1. ed., São Paulo: Dialética, 1999

NOHARA, Irene Patrícia. Direito administrativo. 2. ed. São Paulo: Atlas. 2012.

OTERO, Paulo. Legalidade e Administração Pública: o sentido da vinculação administrativa à juridicidade. Coimbra: Almedina, 2011

PESTANA, Marcio. Direito Administrativo. 3. ed. Rio de Janeiro: Elsevier/Campus. 2012.

REALE, Miguel. Lições Preliminares de direito. 27. ed. 11 tiragem. São Paulo: Saraiva. 2012

RODRIGUES, Marco Antônio dos Santos. Artigo: Neoconstitucionalismo e Legalidade Administrativa: A Juridicidade Administrativa e Sua Relação com os Direitos Fundamentais. Disponível em: download.rj.gov.br/.../rev630309NeoconstitucionalismoPrincipiolleg. Acessado em: 26.12.2012

SERRANO. Pablo Jiménez. Teoria dos Direitos Humanos. São Paulo: Rumo Gráfica Editora. UNIBAN. 2010

SITES

GARCIA, Emerson. A moralidade administrativa e sua densificação. http://jus2.uol. com.br/doutrina/texto.asp?id=4283. Acessado em: 25.10.2012.

www.estig.ipbeja.pt/ ac_direito/DA_I.pdf. Acessado em: 26.12.2012. 